\title{
Children Walking to and from School in Tehran: Associations with neighbourhood safety, parental concerns and children's perceptions
}

\author{
Roya Shokoohi', Noor Rosly Hanif2, Melasutra Md Dali ${ }^{3}$ \\ 1, 2Built Environment, University of Malaya, Malaysia \\ ${ }^{3}$ Art and Social Sciences, University of Malaya, Malaysia \\ royashokoohi@gmail.com
}

\begin{abstract}
Nowadays, children are more likely to use motorized transportation modes to go to and from school. This paper focuses on examining the relationship between neighbourhood safety and primary-aged children walking to and from school on their own; across different socio-economic areas in Tehran. Self-reported parental and children surveys and urban design measurements were used to determine the influence neighbourhood safety factors have on the choice of children's school transportation mode. The results reveal that parents and children with negative perceptions of neighbourhood safety tend to use motor vehicles or to escort their children while walking to and from school.
\end{abstract}

Keywords: Social barriers, walking to and from school, neighbourhood safety, children

eISSN 2514-751X @ 2017 The Authors. Published for AMER ABRA by e-International Publishing House, Ltd., UK.. This is an open access article under the CC BY-NC-ND license (http://creativecommons.org/licenses/by-ncnd/4.0/). Peer-review under responsibility of AMER (Association of Malaysian Environment-Behaviour Researchers), ABRA (Association of Behavioural Researchers on Asians) and cE-Bs (Centre for EnvironmentBehaviour Studies), Faculty of Architecture, Planning \& Surveying, Universiti Teknologi MARA, Malaysia.

https://doi.org/10.21834/aje-bs.v2i3.185 


\subsection{Introduction}

There is general agreement that physical activities are necessary for children's health and their walking to and from school can be a source of daily physical activity. During the past decades, walking to and from school independently was a normal practice in most parts of the world (Ahlport, 2008). However, in recent times parents are often reluctant to allow their children to walk to school on their own. They are concerned about traffic, road conditions and the lack of supervision. However, children's travel mode will affect their future travel behaviour as adults as researches have shown, people stick to their habitual pattern of travel mode (McDonald, 2008). Therefore, children should be targeted to cultivate the habit of walking to and from school, as it has been said:"Habits cultivated at an early age are hard to break" (McMillan, 2005). Moreover, children and the elderly are groups with a low limit of tolerance, which should be considered in the design of streets (Selberg, 1996). As such, considering children as pedestrians means changing the living conditions in the city and starting with the layout of streets and traffic regulations. This includes improving the perception of personal safety in neighbourhoods.

\section{Region of study}

There are many attempts to improve traffic congestion and air pollution, as well as to promote healthy transportation modes both in developed and developing countries. Studies show that traffic congestion and air pollution will be worse in the future in developing countries due to the rapid growth of their population which increases the demand of mobility (Schafer, 1998; Afroz et al., 2003). This factor is likely to be given prominence in any proposal in developing countries for making neighbourhoods safe and convenient for pedestrians.

Tehran is the most populated city in Iran; with a population of $7,872,280$. It covers an area of 754 square meters (Tehran's Master Plan, 2006). Tehran is divided into 22 administrative regions that have been divided into three socio-economic areas (Tehran Master Plan, 2006). Over the last two decades, motor vehicles have emerged as a critical source of urban air pollution in this city (Faiz, 2000; Madanipur, 1999; Atash, 2007). In the last few years, the air pollution level has occasionally reached to such dangerous levels that Tehran's officials had to close

Children Walking to and from School in Tehran schools and impose traffic restrictions (Atash, 2007). Recently, city officials attempted to implement certain policies regarding primary-aged children's school transportation mode in order to reduce traffic jams and air pollution. However, the policies have been designed without a complete understanding of key factors which influence children's travel modes and as such, hit a low point. 


\subsection{Literature Review}

Studies such as Smart Growth found that improving the built environment did not cause people to walk more, as they had not focused on any types of travel (i.e. leisure or work) or any population category. However, these studies did indicate that there are some other influential factors on travel behavior (Handy et al., 2002; Falb et al., 2007; Fyhri et a.l, 2009). Donald Appleyard's work also showed that pedestrian activity is associated with the level of personal safety within a neighbourhood (Appleyard, 2003).

Later in 1997, Safe Routes to School (SR2S) programs, aimed to make the school journey safer and healthier for children. This program assumes a direct relationship between improving the built environment and increasing the number of children walking to and from school. However, the evaluation of SR2S showed that lack of personal safety in a neighbourhood may decrease a child's walking to and from school (Corsi, 2002; Boarnet et al., 2005). Moreover, other studies have shown that for primary school-aged children, physical environmental factors are less important than social factors; parents are more worried about their children being abducted rather than being physically injured (Granville et a.I, 2002; Yeung et a.l, 2008; McNeill et al., 2006).

From the aforementioned personal safety issues are prime concerns for parents when choosing children's travel mode (Merom et al., 2006; McDonald, 2007; Schlossberg et al., 2006; Hume et al., 2009; Wendel et al., 2009). Studies showed parents' comfort level for allowing children to walk to school on their own may be affected by elements of urban design that relate to safety, but rarely went deeper to recognize the specific physical elements which represent neighbourhood safety (Mc Millan, 2003). Studies also showed that the actual level of crime in a neighbourhood is not as is perceived by people. Therefore, to achieve a good result, it is necessary to identify physical elements which are related to the neighbourhood safety, as well as parental and children's perceptions of safety.

The question of what the environmental barriers are for children who are walking to and from school independently, is often complex. However, few studies focused on children's perception of what are the barriers for them while walking to and from school. More importantly, limited studies explained the perception of neighbourhood safety factors across different socio-economic status areas (Pan, 2009; Hamed, 2000).

\section{Aims of Study}

This study tries to explore the association between parental and children's perceptions of personal safety in the neighbourhood with the likelihood of a child's walking to and from school. It further attempts to find out if parents' and children's perceptions of environmental barriers vary across different socio-economic areas. 


\subsection{Methodology}

A cross-sectional survey of parents and children was used to examine data from 18 school sites in Tehran within three different income groups. Qualitative and quantitative data (open-ended and structured questions in a questionnaire) were collected at the same time and all data were transformed into numbers for analysis, so that they can be compared with the quantitative results in the discussion section of the study (Creswell, 2003). All data were analyzed using the statistical program, SPSS-version 17 for Windows.

Cross-tabulation was prepared to show the relationship between independent and dependent variables to examine the environmental barriers for children who walk to and from school on their own. Further significant test (correlation-coefficient) was used to show the strength of the relationships. Finally, ANOVA test was used to determine whether there is any difference between barriers across the areas. Variables were selected from existing literature and parental and children's surveys.

The conceptual framework in Chart 1 draws a conclusion to explore the relationship between neighbourhood safety and children walking to and from school. The framework suggests that several factors impact on how a trip to and from school is made. It shows that socio-economic and socio-demographic factors affect parents' and children's perceptions of safety which also means their perceptions of barriers may vary across different areas. This confirms that, although all the factors are not directly related to children walking to and from school; these factors will assist in developing more comprehensive policies.

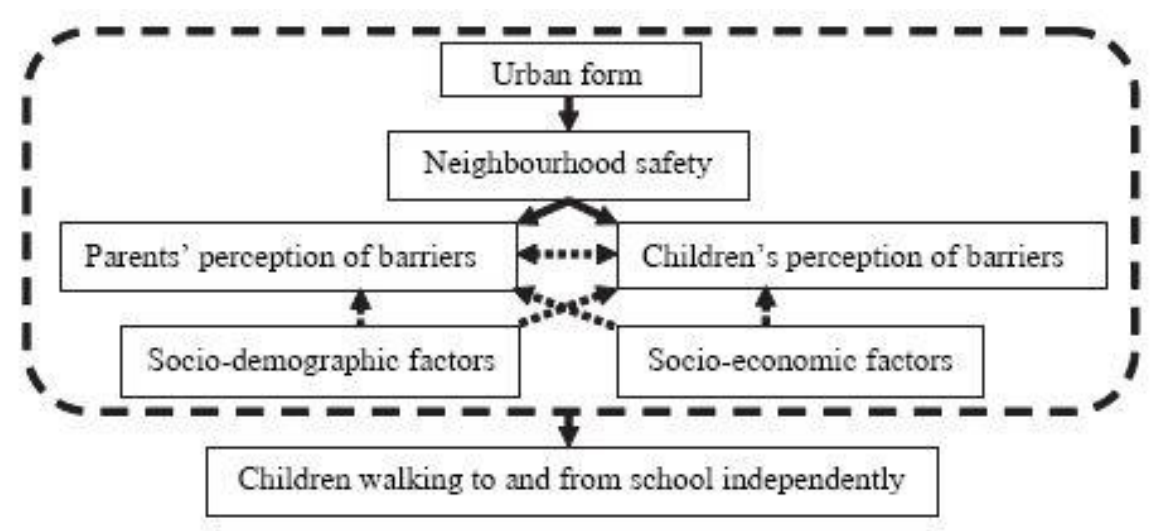

Chart 1: The conceptual framework shows the relationships between neighbourhood safety and travel pattern

Source : Author

\subsection{Research sites}

The study focused on primary government schools in Tehran, because of their neighbourhood orientation, and the tendency of all existing policies to work with this age 
group of children. School catchment areas were stratified into rich, middle and low socioeconomic status (see Figure 1). A multi-stage cluster sampling of schools was arranged, based on a complete list of all primary schools in different areas (see Figure 2) (D.A.de Vaus, 2002). Three districts were excluded from the sampling because the student population was small in these areas. The third one was not under the supervision of the Department of Education and Training in Tehran (District Number 20, 21, 22). Children in Iran go to separate schools in terms of gender from primary till the end of high school. Therefore, two schools were selected from each district, one male and one female, to be fair in gender terms.

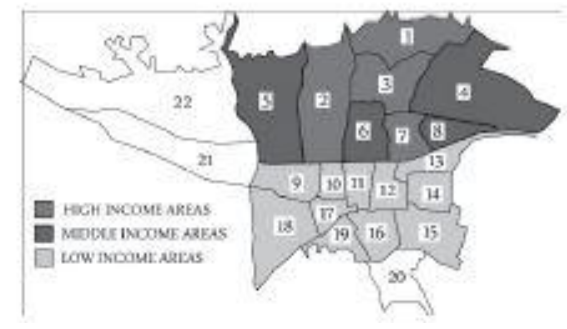

Figure 1: Map of Tehran showing income distribution

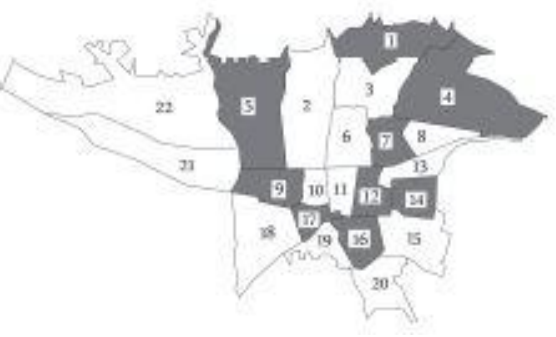

Figure 2: Map of Tehran showing schools catchment areas

\subsection{Data collection procedure}

Data collection was conducted during January and February of 2009. Multiple methods of data collection were used to strengthen reliability as well as internal validity (Merriam, 1988, Tashakkori \& Teddlie, 2003Creswell, 2003). Data collection included parental survey, children's writing activities and some unstructured interviews with them to understand better what they mean.

\section{Parental survey}

The parental survey was designed to extract their perceptions of barriers for children walking to and from school. Parents' surveys were distributed to children, in grades $3-5$, at the selected schools to take home to their parents for their completion. The parents then returned the completed survey to the school via their children the following day. An overall survey response was $56 \%$, and no follow-up was taken to capture non-respondents. The survey included both open-ended and close-ended questions in order to clarify the results of the parental survey (Crump, 2008). In addition, telephone interviews were conducted with parents who did not answer the open-ended questions completely because the researcher did not have direct access to individuals (Creswell, 2007). The questionnaires had different sections including general information, parents' work travel mode, parents' feelings and 
decisions about their children's travelling to and from school, parents' school travel mode and parent's perceptions of safety in the immediate school environment.

\section{Children's survey}

Children of all three age groups were invited to participate in the survey, including children who walked to and from school and those who did not. After explaining the purpose of the study to them, volunteer students were asked to fill up a simple chart showing environmental factors that prevented them from walking to and from school on their own.

They were further asked to write a composition about their journey to and from school and some of them were interviewed later on to clarify and understand what the children meant (Creswell, 2007; Yin, 2003). Using a writing method for collecting data from children helped the researcher to obtain data more quickly and from a greater number of children (Boyden \& Ennew, 1997; Cameron, 2005; Sinclair, 2004). Some questions were asked of both parents and children, to see if it was possible to establish a linkage between the answers of the children and those of their parents.

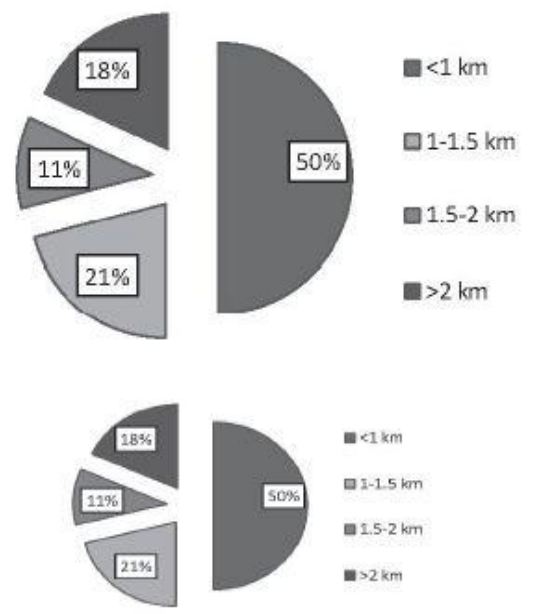

Chart 2: Parents' report about children's travelling distance from home toschool Source: Author

\subsection{Results and Discussions}

There were almost equal male and female children in the sample to be fair in gender (51.2\% female, $48.8 \%$ male). Children were also distributed equally across different grades. According to previous research, the most important barrier for children in their walking to and from school is the distance from home to school (Granville et al., 2002; McMillan, 
2003). In this study the majority of the children lived less than $1 \mathrm{~km}$ from school, however, only a few of them walked to school, especially on their own.

To understand if any factors in the environment impede children's walking to and from school, we need to know both their current and favourite travel mode to school. Also, we should know the reasons if they cannot meet their desirable school transportation. When parents and children were asked about how the children usually go to school, about $42 \%$ mentioned walking as a main school travel mode. However, more than $20 \%$ of children walked with their parents or older siblings. Most importantly, there were some differences between a child's transportation mode to and from school.

Walking was still the predominant travel mode in the afternoon (back home from school). Children were more likely to walk with their friends on their trip back home from school. Few students used public transportation and nobody chose cycling or skating to and from school, so these were excluded from further analysis. This may be explained by poorly planned roads for cycling and skating, and weather conditions during school time. It may also be due to cultural and social norms in Iran regarding biking and skating on the streets, especially for girls. Being driven by parents had a higher rate among high-income groups, while students from low-income groups had the highest rate of walking to and from school.

Table 1: Respondents' report about children's current travel mode to and from school

\begin{tabular}{lcc}
\hline Child's transportation modes & $\begin{array}{c}\text { Child's current travel mode } \\
\text { to school }\end{array}$ & $\begin{array}{c}\text { Child's current travel mode } \\
\text { from school }\end{array}$ \\
\hline Walk with friends & 5.6 & 19.4 \\
Walk with parents & 27.4 & 24.6 \\
Walk with siblings & 3.2 & 2 \\
Walk alone & 11.9 & 10.3 \\
Driven by parents & 20.2 & 8.7 \\
By public transportation & 3.6 & 4.4 \\
By school bus & 28.2 & 30.6 \\
\hline
\end{tabular}

Parents and children were further asked about the most convenient transportation mode to school for their children. The majority of parents reported walking was the best school transportation mode for their children if they could escort them. Only a few of them thought that children walking with their friends, or on their own to school was a proper school travel mode. On the contrary, over $36 \%$ of the children reported they would like to walk to school with their friends, and the rate increased slightly on their return trip home from school. Approximately $43 \%$ of parents reported lack of personal safety in the neighbourhood as the main reason why they preferred their children not to walk to and from school. To understand which neighbourhood safety elements were associated with a child's walking to school, cross-tabulation and correlation coefficient were done.

Variables relating to personal safety in a neighbourhood from parents' and children's surveys were included in the analysis. Children's school transportation modes were limited to walking with friends or alone, walking with an adult or elder sibling, being driven by 
parents and using the school bus. Four items focused on adult supervision, general safety in the neighbourhood and the number of pedestrians on the street were factors which may have an influence on the parents' perception of safety for their children's walking to and from school. Two items which focused on personal safety in the neighbourhood were factors that may have an effect on children's perception of safety while walking to school. The results are summarized in Table 1.

Table 2 provides the correlation coefficient and significance levels for cross-tabulations between children's travel mode to school and their parents' perception of safety in the neighbourhood. The variables which are related to parental perception of safety in the neighbourhood were: 1) If one of the parents or an adult whom they know walked with the child to school, 2) If a lot of children walk to school together,3) If there are a lot of pedestrians on the street and 4) Presence of safety in the neighbourhood.

Table 2: The different strength of association between a child's trip to school and parental perception of personal safety in the neighbourhood.

\begin{tabular}{|c|c|c|c|c|c|c|c|c|c|c|c|c|}
\hline Whitrow hed and & 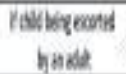 & ancita & provas & $\begin{array}{l}\text { Weraliben } \\
\text { whosed }\end{array}$ & wnikn & spious & 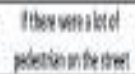 & areibn & żpinzu & 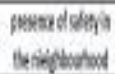 & ontrim : & phos: \\
\hline divitget & 1018 & 121 & WI & 0 & 132 & (15) & 118 & I0 & 181 & 152 & Q17? & 152 \\
\hline detopes & 45: & $8 \pi$ & $\theta$ & OAB & 1s: & an & 213 & II5 & 15: & 989 & $0 \times 5$ & LII \\
\hline distodrolet & 13 & 142 & 0 & $\Delta x$ & 036 & 155 & $18 \mathrm{~B}$ & IN & 178 & at? & Q155 & IK \\
\hline diter & 내태 & M & W & 0 & $\Delta 4$ & 1010 & 45 & 128 & ISt & WI! & a & LI \\
\hline tivety yexs & is & is & (X) & OtII & ats & $\omega 0$ & 100 & 130 & 14 & 84 & 027 & 1008 \\
\hline butad bs & 217 & 128. & 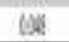 & 21 & 445 & L18 & 148 & 42 & 100 & ay & oxe & 142 \\
\hline
\end{tabular}

Source: Author

The relationships between "parent or adult whom parent knows, walks with the child" and children's walking to school (with friends, and parents) were very strong. The significance level of 0.000 indicates that this strong relationship was most likely to hold in the population surveyed. rather than occurring due to sampling error. "Parent or an adult whom the parent knows walks with the child to school" has moderate association with a child's walking to school alone, with an elder sibling, being driven by parents and using school bus. All relationships reflect the population.

It could be explained that only a few parents who sent their children to school by car or school bus would let their children walk to school if they could walk with them.

The relationship between children being driven by parents and "if a lot of children walk to school" is moderate, and the relationship is most likely to hold in the population surveyed. It indicates that some of the parents who chauffeured their children to school would allow their children to walk to school, if a lot of children walked to school. "If there are a lot of pedestrians on the street" and sending a child to school by school bus, reflected a moderate relationship in the population surveyed $(s i g=0.004)$. It showed that few parents 
whose children currently use the school bus would allow their children to walk to school if the number of people who walked on the street increased. The association between other children's school transportation and these variables was neither strong nor at the significance level of 0.000 .

Children's perception of personal safety in the neighbourhood was limited to "I am scared of being abducted" and "I am scared of being abused by building workers". However, there are no relationships between children's travel modes to school and those variables. It can be explained that parents were more likely to be the final decision-makers about their children's travel mode to school, and children's perception of safety in the neighbourhood did not affect their decision.

To identify whether there is any difference between variables which represent parents' perceptions of personal safety in the neighbourhood and their children's travel mode to school, the ANOVA test was used (see Table 3).

Table 3: F-test of "children's walking with parents or an adult whom the parents know" by different socio-economic status areas

\begin{tabular}{|c|c|c|c|c|c|c|}
\hline & & $\begin{array}{l}\text { Sun of } \\
\text { Squares }\end{array}$ & df & $\begin{array}{l}\text { Mean } \\
\text { Square }\end{array}$ & $F$ & Sig. \\
\hline $\begin{array}{l}\text {...you or an adult you } \\
\text { knew could walk with } \\
\text { him/her }\end{array}$ & $\begin{array}{l}\text { Between Groups } \\
\text { Within Groups }\end{array}$ & $\begin{array}{c}1.411 \\
253.670\end{array}$ & $\begin{array}{c}2 \\
181\end{array}$ & $\begin{array}{l}.706 \\
1.401\end{array}$ & .504 & .605 \\
\hline $\begin{array}{l}\text {...the neighbourhood } \\
\text { was safer }\end{array}$ & $\begin{array}{l}\text { Between Groups } \\
\text { Within Groups }\end{array}$ & $\begin{array}{c}2.682 \\
262.711\end{array}$ & $\begin{array}{c}2 \\
152\end{array}$ & $\begin{array}{l}1.341 \\
1.728 \\
\end{array}$ & .776 & .462 \\
\hline $\begin{array}{l}\text {..there were more } \\
\text { people who walked in } \\
\text { the neighbourhood }\end{array}$ & $\begin{array}{l}\text { Between Groups } \\
\text { Within Groups }\end{array}$ & $\begin{array}{c}2.733 \\
123.069\end{array}$ & $\begin{array}{c}2 \\
78\end{array}$ & $\begin{array}{l}1.367 \\
1.578\end{array}$ & .866 & .425 \\
\hline $\begin{array}{l}\text {...other children } \\
\text { walked together to } \\
\text { from school }\end{array}$ & $\begin{array}{l}\text { Between Groups } \\
\text { Within Groups }\end{array}$ & $\begin{array}{c}.698 \\
67.234\end{array}$ & $\begin{array}{c}2 \\
56\end{array}$ & $\begin{array}{r}.349 \\
1.201\end{array}$ & 291 & .749 \\
\hline
\end{tabular}

Source: Author

The significance levels in the ANOVA test indicate that there is no difference between parental perceptions of neighbourhood safety barriers across different socio-economic status areas in Tehran. Parents preferred to walk with their children to school rather than allow them to walk on their own, and the number of pedestrians on the street (adult or children) did not significantly affect parental decision-making about their children's walking to school. Finally, the level of safety in the neighbourhood may increase the number of children who walk to school, but this does not stop parents from walking with their children to school. However, more studies are needed to find out how parental perception of personal safety could be improved, especially through the physical elements of the environment. 


\subsection{Conclusion}

Several definitions and measures of social safety exist. The findings were consistent with the results obtained from other studies that showed that the ${ }^{23}$ most important dimension of social safety for children's trips to school was parental perception about personal and traffic safety in neighbourhoods (McNeill et al., 2006; Lochner et al., 1999). Moreover, children's feelings about personal safety in a neighbourhood did not change the relationships. The results also indicated that parents who had negative perceptions of neighbourhood safety tended to use motorized modes more than walking with their children to and from school. It also revealed that low-income children had a higher rate of walking to and from school, because they would like to avoid travel costs. The findings highlighted although children's travel mode to school varied across different areas, parental perception of safety in the neighbourhood did not vary among different income groups. This can be because there are some other variables that affect parental decision-making about their children's mode of travelling to school besides neighbourhood safety

\section{Acknowledgement}

I would like to give my sincere thanks to my supervisors Assoc. Prof. Dr. Noor Rosly Hanif and Assoc. Prof. Dr. Melasutra Md Dali for their help and support.

\section{References}

Ahlport, K.N., Linnan, L., Vaughn, A., Evenson, K.R., \&Word D.S. (2008). Barriers to and facilitators of walking and bicycling to school: formative results from the non-motorized travel study. Health Education Behaviour, 35, 221244.

Appleyard, B. S. (2003). Planning safe routes to school; "How will my child get to and from school?". Planning, 69.

Afroz, R., Hassan M.N., \& Ibrahim A.A.(2003). Review of air pollution and health impacts in Malaysia. Environmental Research, 92, 71-77.

Atash, F. (2007).The deterioration of urban environments in developing countries: Mitigating the air pollution crisis in Tehran, Iran. Cities, 24(6), 399-409.

Boarnet, M. G., Anderson, G. L., Day, K., \& McMillan, T. (2005). Evaluation of the California Safe Routes to School: Legislation, Urban form changes and children's active transportation to school. American Journal of Preventive Medicine, 28(2S2), 134-140.

Corsi, M. (2002). The child friendly cities initiative in Italy. Environment and Urbanization, 14(2), 169-179.

Creswell, J. W. (2003). Research Design: Qualitative, Quantitative, and Mixed Methods Approaches (2nd Edition). California: Sage Publications. 
Falb, M. D., Kanny, D., Powell, K. E., \& Giarrusso, A. J. the Proportion of Children Who Can Walk to School. American Journal of Preventive Medicine, 33(4), 269-275.

Granville, S., Laird, A., Barber, M., \& Rait, F. (2002). Why do parents drive their children to school?(Transport Research Series). Scotland: Scottish Executive Central Research Unit.

Hamed, M. M., \& Olaywah, H. H. (2000).Travel-related decisions by bus, service taxi and private car commuters in the city of Amman,Jordan. Cities, 17(1), 63-71.

Handy, S. (2005). Smart Growth and the transportation-land use connection: What does the research tell us? International Regional Science Review,28(2), 146-167.

Harcourt, B. E., \& Ludwig, J. (2006). Broken Windows: New Evidence from New York City and a Five-City Social Experiment. The University of Chicago Law Review: Symposium: Homo Economicus, Homo Myopicus, and the Law and Economics of Consumer Choice, 73(1), 271-320.

Holt, N. L., Spence, J. C., Sehn, Z. L., \& Cutumisu, N. (2008). Neighborhood and developmental differences in children's perceptions of opportunities for play and physical activity. Health \& Place, 14, 2-14.

Madanipour, A. (1999). City profile Tehran. Cities, 16(1), 57-65.

McDonald, N. C. (2008). Critical factors for active transportation to school among low-income and minority studentsevidence from the 2001 National Household Travel Survey. American Journal of Preventive Medicine, $34(4)$, 341-344.

McMillan, T. E. (2005). Urban form and a child's trip to school: The current literature and a framework for future research. Journal of Planning Literature, 19, 440-454.

McMillan, T. A. (2003). Walking and urban form: Modeling and testing parental decisions about children's travel (Doctoral Dissertation). Retrieved from ProQuest digital dissertations. (UMI 3090273).

Selberg, K. (1996). Road and traffic environment. Landscape and Urban Planning, 35, 153-172.

Ulfarsson , G. F., \& Shankar, V. N. (2008). Children's travel to school: discrete choice modeling of correlated motorized and non-motorized transportation modes using covariance heterogeneity. Environment and Planning B: Planning and design, 35, 195-206.

Wendel, A. M., \& Dannenberg, A. L. (2009). Reversing declines in walking and bicycling to school. Preventive Medicine, 48, 513-515

Yeung, J., Wearing, S., \& Hills, A. P. (2008). Child transport practices and perceived barriers in active commuting to school. Transportation Research Part A, 1-5. 